\title{
Conservation genetics of Annamocarya sinensis (Dode) Leroy, an endangered endemic species
}

\author{
Z.Y. Zhang, X.M. Pang, J.W. Han, Y. Wang and Y.Y. Li \\ National Engineering Laboratory for Tree Breeding of the National Development \\ and Reform Commission, College of Biological Sciences and Technology, \\ Beijing Forestry University, Beijing, China \\ Corresponding author: Y.Y. Li \\ E-mail: yingyueli@bjfu.edu.cn
}

Genet. Mol. Res. 12 (3): 3965-3974 (2013)

Received July 24, 2012

Accepted November 31, 2012

Published March 11, 2013

DOI http://dx.doi.org/10.4238/2013.March.11.9

\begin{abstract}
The endangered perennial plant Annamocarya sinensis (Dode) Leroy is a tertiary relict tree restricted to southeastern China and northern Vietnam. To explore endangerment mechanisms, develop protection strategies, and guide reintroduction efforts for this species, we investigated genetic diversity and population structure by surveying 70 individuals from three distinct populations using 12 polymorphic microsatellite markers. We found high genetic diversity for $A$. sinensis as indicated by high allelic diversity (allelic number $=4.667 \pm 0.436$, effective number of alleles $=2.913 \pm 0.249$ ), excess heterozygosity (observed heterozygosity $=0.586 \pm 0.039$, expected heterozygosity $=0.582 \pm 0.029$ ), and low fixation index $(-0.028 \pm 0.057)$. Our research revealed low genetic differentiation $\left(F_{\mathrm{ST}}=0.066 \pm 0.011\right)$ and no correlation between genetic distance and geographic distance. Analysis of molecular variance attributed $87 \%$ of the variance to differences within the population, whereas $13 \%$ was distributed among populations. The protection strategy should aim to protect as many populations as possible. Promoting
\end{abstract}


sexual reproduction among various genotypes and establishing an outcrossing program are advisable for $A$. sinensis.

Key words: Genetic diversity; Population structure; Microsatellite; Endangered species; Annamocarya sinensis

\section{INTRODUCTION}

Effective conservation management and restoration efforts directed at endangered species require knowledge and analysis of the genetic variation within and among remnant populations to assess population genetic diversity and structure as well as within-population micro-evolutionary potential (Karron, 1987; Elam, 1998; Reed and Frankham, 2003). Compared with relatively abundant species, rare species always exhibit less genetic variation among individuals and populations. Thus, they have a lower percentage of polymorphisms, lower number of alleles, and lower observed and expected heterozygosity ( $H_{\mathrm{O}}$ and $H_{\mathrm{E}}$, respectively) (Karron, 1987; Cole, 2003).

For most species, habitat loss and degradation may be a main cause of population isolation, decline, or extinction. However, in terms of endangered species, conservation of genetic variation is considered a vital factor for long-term survival (Hamrick et al., 1991; Falk, 1992). Spielman et al. (2004) have proposed that most populations of rare species are affected by genetic factors well before stochastic events lead to population extinction. An increasing number of studies have demonstrated the value of genetic data in addressing issues of plant conservation biology, especially for providing conservation recommendations and determining conservation strategies for endangered species (Sosa et al., 2010).

In recent years, simple sequence repeats (SSRs, or microsatellites) have become some of the most useful markers for genetic variation analysis. Their advantages include high levels of polymorphism, co-dominance, reproducibility, and transferability (Toth et al., 2000). As a result, mining SSRs from expressed sequence tags (ESTs) is an important method by which SSR markers can be identified (Ellis et al., 2006). Compared with anonymous SSRs, ESTSSRs are derived from transcribed sequences and generally show a higher level of transferability; thus, they have the potential for direct linkage association with functional genes (Leigh et al., 2003; Rungis et al., 2004). Over the past decade, a large amount of DNA sequence data including ESTs have been generated in many plants via advances in genomic technology (Gupta et al., 1996). These data have become rich sources of SSR identification and provide cost-effective, labor-efficient means for SSR marker development.

Annamocarya sinensis (Dode) Leroy is the only species of the genus Annamocarya (family Juglandaceae) native to southwestern China and northern Vietnam bordering China. Owing to its reduced and limited number of individuals, $A$. sinensis has been listed as a critically endangered species in China and was given as second class state protection in the Chinese Red Data Book in 1992. According to the latest data, the number of naturally occurring individuals is between 100 and 1000 (Gu, 2003). Anthropogenic and natural factors have fragmented many natural habitats in recent years, some of which have even been lost to woodland or commercial collection (personal observation). The main goals of this study were to 1) analyze the genetic diversity and structure within and among $A$. sinensis populations, 2 ) infer potential evolutionary processes that could have led to the endangerment of this species, and 3) use the genetic information obtained as a tool with which to design conservation strategies for the species. 


\section{MATERIAL AND METHODS}

\section{Population and sampling}

All remnant populations in the natural range of $A$. sinensis were surveyed between April and December 2011 to obtain basic knowledge of this endangered species. We found 81 adult individuals in 6 sites that are believed to exceed 100 years in age, and the diameter at breast height was $>50 \mathrm{~cm}$. The precise geographic location was determined using a Garmin (Xinbei, Taiwan) global positioning system device (Table 1). In the sites of Yongfu, Xichou, and Nandan, the shortest distance between two areas (Yongfu and Nandan) was $>108.85 \mathrm{~km}$. And in each site, individuals were isolated and dispersed, with a very small number of adult individuals in the same area. To obtain accurate statistics, these three sites were not used in further analysis. So populations were located in three groups: Sandu (19 adult individuals in an area $\left.1 \mathrm{~km}^{2}\right)$, Funing (16 individuals within $0.7 \mathrm{~km}^{2}$ ), and Malipo (35 individuals within $4 \mathrm{~km}^{2}$ ), among which nine individuals were in northern Vietnam bordering China and all individuals were sparsely distributed.

\begin{tabular}{|c|c|c|c|c|}
\hline Site & Site code & Latitude & Longitude & Sample size \\
\hline Sandu, Guizhou & SD & $26^{\circ} 02.795^{\prime} \mathrm{N}$ & $107^{\circ} 57.611^{\prime} \mathrm{E}$ & 19 \\
\hline Funing, Yunnan & $\mathrm{FN}$ & $23^{\circ} 35.347^{\prime} \mathrm{N}$ & $105^{\circ} 38.983^{\prime} \mathrm{E}$ & 16 \\
\hline Malipo, Yunnan & MLP & $23^{\circ} 07.626^{\prime} \mathrm{N}$ & $104^{\circ} 51.643^{\prime} \mathrm{E}$ & 35 \\
\hline Xichou, Yunnan & $\mathrm{XCH}$ & $23^{\circ} 16.166^{\prime} \mathrm{N}$ & $104^{\circ} 58.131^{\prime} \mathrm{E}$ & 6 \\
\hline Yongfu, Guangxi & YF & $24^{\circ} 49.149^{\prime} \mathrm{N}$ & $110^{\circ} 01.772^{\prime} \mathrm{E}$ & 1 \\
\hline Nandan, Guangxi & ND & $25^{\circ} 15.793^{\prime} \mathrm{N}$ & $107^{\circ} 10.386^{\prime} \mathrm{E}$ & 4 \\
\hline
\end{tabular}

In total, 70 naturally occurring adult individuals of $A$. sinensis from all three of these populations were sampled. Leaves were collected and stored with silica gel in labeled zipsealable bags until use.

\section{EST-SSR primer development}

In total, 13,559 ESTs of Juglans hindsii x Juglans regia were retrieved from the National Center of Biotechnology Information database on November 3, 2011. After removing redundant and junk sequences, unigenes (including contigs and singletons) were assembled using the Seqman module of the DNAStar software (Steve Shear Down 1998-2001, version reserved by DNASTAR Inc., Madison, WI, USA), which were scanned with a PERL script designed to identify SSR-containing sequences comprising di-, tri-, tetra-, penta-, and hexanucleotide repeats with a minimum of $6,5,5,4$, and 4 subunits, respectively. Primer pairs flanking repeats were designed using online PRIMER 3 and then synthesized by Sangon Biotech (China).

\section{DNA extraction and polymerase chain reaction (PCR) amplification}

DNA was extracted from silica-gel-dried young leaves using a modified $2 \mathrm{X}$ cetyltrimethylammonium bromide protocol (Doyle and Doyle, 1987). The quality of DNA was checked using electrophoresis on 1\% agarose gel, and the DNA concentration was determined with a spectrophotometer. 
An M13-tagged sequence (5'-TGTAAAACGACGGCCAGT-3') was added to the 5 '-end of the forward primer to allow detection with a universal fluorescent-labeled M13 primer. Each PCR used a $20-\mu \mathrm{L}$ total volume containing $10 \mu \mathrm{L} 2 \mathrm{X}$ Tap PCR Mix (Biomedtech, Beijing, China), $4 \mu \mathrm{L} 4$ pmol fluorescent-dye-labeled (FAM, HEX, TAMRA, ROX) M13 primer, $4 \mu \mathrm{L} 4$ pmol mixed complementary forward and reverse primers, and $2 \mu \mathrm{L}(\sim 10 \mathrm{ng})$ genomic DNA. PCR amplifications were performed in a GeneAmp ${ }^{\circledR}$ PCR System 9700 thermal cycler (Bio-Rad Laboratories Inc., Beijing, China) using the following program: $94^{\circ} \mathrm{C}$ for $10 \mathrm{~min}$, followed by 30 cycles of $30 \mathrm{~s}$ at $94^{\circ} \mathrm{C}, 40 \mathrm{~s}$ at $56^{\circ} \mathrm{C}$, and $72^{\circ} \mathrm{C}$ for $40 \mathrm{~s}$; then 8 cycles of $30 \mathrm{~s}$ at $94^{\circ} \mathrm{C}, 40 \mathrm{~s}$ at $53^{\circ} \mathrm{C}$, and $72^{\circ} \mathrm{C}$ for $40 \mathrm{~s}$, with a final extension at $72^{\circ} \mathrm{C}$ for $10 \mathrm{~min}$; and $10^{\circ} \mathrm{C}$ indefinitely. The PCR products were resolved using an ABI 3730XL DNA Analyzer by Genewiz Biotechnology Co., Ltd., (Beijing, China), and the data were analyzed with the Gene-Marker software (SoftGenetics LLC, State College, PA, USA).

\section{Statistical analysis}

\section{Genetic diversity}

The genetic diversity indices, including the number of alleles per locus $\left(N_{\mathrm{A}}\right)$, effective number of alleles $\left(N_{\mathrm{E}}\right), H_{\mathrm{O}}$, and $H_{\mathrm{E}}$, Shannon's information index, and fixation index, were calculated at both the species and population levels using ARLEQUIN 3.11 (Excoffier and Schneider, 2005) and GENALEX 6.2 (Peakall and Smouse, 2006). The polymorphic information content was analyzed using CERVUS 3.0 (Marshall et al., 1998). FSTAT (Goudet, 1995) was used to test the number or frequency of private alleles and unique multi-locus genotypes among populations, and deviation from Hardy-Weinberg equilibrium (HWE) was determined using the Fisher exact test.

\section{Population structure}

Using ARLEQUIN version 2.000 (Schneider et al., 2000), multi-locus pairwise F-statistics were quantified, and the hierarchical structure of genetic variation among populations was determined with analysis of molecular variance (Excoffier et al., 1992). Principal coordinate analysis was also conducted to visualize clusters among individuals and populations according to genetic distance using GENALEX 6.2 (Peakall and Smouse, 2006).

Population structure was inferred using a model-based Bayesian clustering procedure implemented with the STRUCTURE software (Pritchard et al., 2000) to determine a priori grouping of the populations. A no-admixture model and correlated allele frequencies were used. Eight independent runs of $\mathrm{K}=1-8$ were performed at 10,000 Markov chain Monte Carlo repetitions with a 10,000 burn-in period. The optimum number of clusters was determined by combining the recommendations of Pritchard et al. (2000) and the approach of Evanno et al. (2005).

\section{Isolation by distance and bottleneck}

To test the presence of isolation by distance among $A$. sinensis populations, we performed the Mantel test (Mantel, 1967) between the matrix of pairwise population differentiation and the matrix of geographical distances using GENALEX6.2 (Peakall and Smouse, 2006). Further, to test for evidence of recent genetic bottlenecks, we performed the Wilcoxon 
signed-rank test of heterozygosity of excess under the infinite allele model (IAM), stepwise mutation model (SMM), and two-phase model (TPM). A mode shift away from an L-shaped distribution of allelic frequencies was also approached. These analyses were conducted using BOTTLENECK 1.2.02 (Piry et al., 1999).

\section{RESULTS}

\section{EST-SSRs}

In total, $706 \mathrm{SSR}$-containing unigenes, including 256 contigs and 450 singletons, were obtained after assembly and scanning of the 13,559 ESTs. In total, 192 SSR primer pairs were arbitrarily developed and synthesized. To test their capability to yield amplification products of the expected sizes, we first screened all primers in a panel of 16 individuals from different populations, and found 70 primers to be positive in this species. Based on the polymorphism rate revealed, 12 pairs were selected for further analysis among the 70 samples (Table 2).

\begin{tabular}{|c|c|c|c|c|c|c|c|}
\hline Locus & Forward $\left(5^{\prime}-3^{\prime}\right) / /$ Reverse $\left(5^{\prime}-3^{\prime}\right)$ & $\begin{array}{c}\text { Repeat } \\
\text { motif }\end{array}$ & $\begin{array}{l}\text { Allele } \\
\text { size }\end{array}$ & PIC & $H_{\mathrm{O}}$ & $H_{\mathrm{E}}$ & $\mathrm{F}$ \\
\hline BJFAS-107 & CAGGAGGGTAAGGTGGTGAA//CACAACCAAAGCAAAACTTCC & $(\mathrm{TA})_{6}$ & 196 & 0.233 & 0.233 & 0.242 & 0.037 \\
\hline BJFAS-180 & GAAGAGATGGAGGAGGCAAA//GTTTGACGGGAAACGAGAAA & $(\mathrm{CAG})_{7}$ & 213 & 0.479 & 0.794 & 0.571 & -0.391 \\
\hline BJFAS-57 & GAGAAATGATGGGGTGCCTA//CAAACCGGAGGTCTCTGAAG & $(\mathrm{AGA})_{6}$ & 304 & 0.358 & 0.486 & 0.467 & -0.040 \\
\hline BJFAS-6 & CAAAAACGATGGCAGTTGAT//ACCAACACTCGGGTATGCTC & $(\mathrm{TA})_{6}$ & 120 & 0.777 & 0.657 & 0.806 & 0.185 \\
\hline BJFAS-170 & CGAGTAGGAACCCGATTCAA//CAGCCAAAAGGAAGAGCAAG & $\begin{array}{c}(\mathrm{AGAA})_{5} \\
(\mathrm{AG})_{13}\end{array}$ & 198 & 0.546 & 0.571 & 0.579 & -0.014 \\
\hline BJFAS-65 & CGATTAGCAATAGCGGAAGC//ATGGGGAACTGCAGAAACAG & $(\mathrm{GCA})_{7}$ & 263 & 0.376 & 0.643 & 0.488 & -0.316 \\
\hline BJFAS-16 & TTCCACTTCCTGGACCTCAC//ATTTATCCCGATGACCCACA & $(\mathrm{CT})_{17}$ & 234 & 0.865 & 0.746 & 0.877 & 0.149 \\
\hline BJFAS-189 & GCTACGATGGTCAGGGTTTC//GACACGATTTCTTCGCCTTC & $\begin{array}{l}(\mathrm{TC})_{7} \\
(\mathrm{TC})_{7}\end{array}$ & 275 & 0.413 & 0.217 & 0.506 & 0.572 \\
\hline BJFAS-72 & CAGGCCAATTCTTCACCATT//GCCTCTATTCAAAAACCAGCTT & $\begin{array}{l}(\mathrm{TA})_{7} \\
(\mathrm{TG})_{6}\end{array}$ & 357 & 0.675 & 0.682 & 0.722 & 0.056 \\
\hline BJFAS-192 & СССТСТТСССТСААССТСТC//GAACACTTCСТCTCGCTTGG & $(\mathrm{TCT})_{6}$ & 181 & 0.621 & 0.986 & 0.679 & -0.451 \\
\hline BJFAS-4 & CCAAGGCATCCTCCTTAACA//ATGGCTGGTCGTTTGCTAGT & $(\mathrm{TC})_{11}$ & 231 & 0.746 & 0.493 & 0.762 & 0.353 \\
\hline BJFAS-79 & CAAGAAGCTGGACCCAGAAG//ACGTGAAGAGCAGGTGGAGT & $(\mathrm{TG})_{10}$ & 150 & 0.868 & 0.543 & 0.880 & 0.383 \\
\hline Mean & - & - & - & - & 0.588 & 0.632 & 0.046 \\
\hline
\end{tabular}

$\mathrm{PIC}=$ polymorphism information content; $H_{\mathrm{O}}=$ observed and $H_{\mathrm{E}}=$ expected heterozygosities.

\section{Genetic diversity}

Twelve microsatellite loci were used to analyze the genetic diversity and population structure of $A$. sinensis. The 12 microsatellite loci generated a total of 77 observed alleles ranging from 2 to 13 and 162 observed multi-locus genotypes ranging from 4 to 31 at the species level (data not shown). Meanwhile, in total, 21 private alleles and 89 unique multi-locus genotypes were also detected, of which 8,2, and 11 and 21, 13, and 55, respectively, were specific to Sandu, Funing, and Malipo, respectively (Table 3 ). These results suggested a relatively high average genetic diversity within and among populations $\left(N_{\mathrm{A}}=4.667 \pm 0.436 ; N_{\mathrm{E}}=2.913 \pm\right.$ $0.249 ; H_{\mathrm{O}}=0.586 \pm 0.039$, and $H_{\mathrm{E}}=0.582 \pm 0.029$; Shannon's information index $=1.117 \pm$ 0.082 ; fixation index $=-0.028 \pm 0.057$ ). Single-locus exact tests for HWE indicated significant deviations in 18 of 36 comparisons $(\mathrm{P}<0.05)$. 
Table 3. Genetic variation at 12 microsatellite loci at the population level.

\begin{tabular}{lcccccrrr}
\hline Pop. & $N_{\mathrm{A}}$ & $N_{\mathrm{E}}$ & $I$ & $H_{\mathrm{O}}$ & $H_{\mathrm{E}}$ & $F$ & $\begin{array}{c}\text { No. alleles } \\
\text { - private }^{\mathrm{a}}\end{array}$ & $\begin{array}{c}\text { No. genotypes } \\
- \text { unique }^{\mathrm{b}}\end{array}$ \\
\hline SD & $4.333 \pm 0.582$ & $2.619 \pm 0.246$ & $1.081 \pm 0.11$ & $0.561 \pm 0.058$ & $0.578 \pm 0.042$ & $0.010 \pm 0.085$ & $52-8^{\mathrm{a}}$ & $71-21^{\mathrm{b}}$ \\
FN & $4.083 \pm 0.733$ & $2.692 \pm 0.397$ & $1.015 \pm 0.151$ & $0.599 \pm 0.079$ & $0.545 \pm 0.059$ & $-0.126 \pm 0.105$ & $49-2^{\mathrm{a}}$ & $61-13^{\mathrm{b}}$ \\
MLP & $5.583 \pm 0.908$ & $3.427 \pm 0.581$ & $1.256 \pm 0.163$ & $0.597 \pm 0.071$ & $0.622 \pm 0.051$ & $0.031 \pm 0.105$ & $67-11^{\mathrm{a}}$ & $122-55^{\mathrm{b}}$ \\
Total & $4.667 \pm 0.436$ & $2.913 \pm 0.249$ & $1.117 \pm 0.082$ & $0.586 \pm 0.039$ & $0.582 \pm 0.029$ & $-0.028 \pm 0.057$ & $77-21^{\mathrm{a}}$ & $162-89^{\mathrm{b}}$ \\
\hline
\end{tabular}

$N_{\mathrm{A}}=$ number of observed alleles; $N_{\mathrm{E}}=$ number of expected alleles; $I=$ Shannon's information index; $H_{\mathrm{O}}=$ observed heterozygosity; $H_{\mathrm{E}}=$ expected heterozygosity; $F$ = fixation index; ${ }^{\mathrm{A}}$ number of alleles and private alleles in each population; ${ }^{b}$ number of genotypes and unique genotypes in each population. For population (Pop.) abbreviations, see Table 1.

\section{Population structure}

F-statistics between paired populations ranged from 0.034 to 0.074 , with means \pm standard error of $0.066 \pm 0.011$, indicating an extremely low level of genetic differentiation among wild populations. The highest level was between the Sandu and Funing populations, and the lowest was between Malipo and Funing. Inbreeding coefficient ranged from -0.552 to 0.481 with means \pm standard error of $-0.024 \pm 0.090$.

Analysis of molecular variance analysis revealed that $87 \%$ of the genetic variation was distributed among individuals within populations, and the remaining $13 \%$ was distributed among populations.

In the model-based Bayesian analysis, the $\mathrm{LnP}(\mathrm{D})$ data showed an increase up to $\mathrm{K}=$ 2 , but for $\mathrm{K}>2$, the extent of increase in information decreased. These results suggested that the optimum number of K was 2. The analysis indicates that the Sandu and Funing populations belong to a single homogeneous population cluster. The population of Malipo showed mixed ancestry, suggesting a degree of genetic mixing (Figure 1).

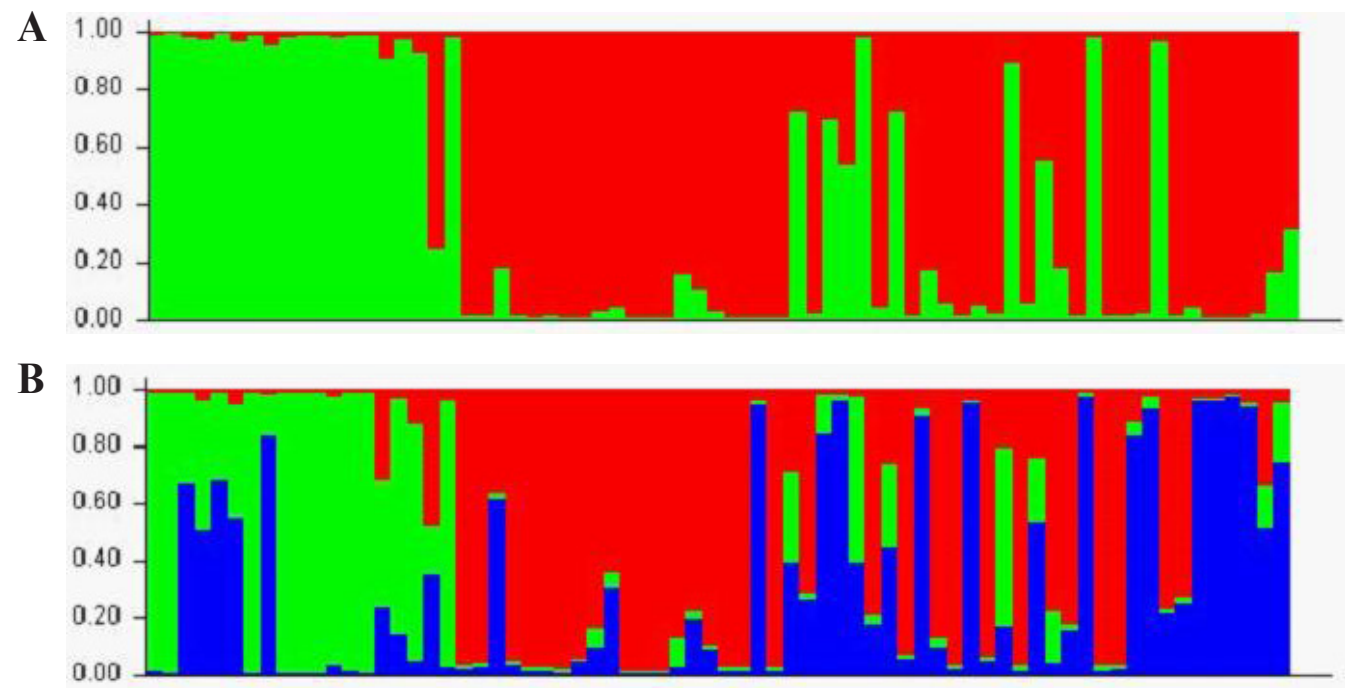

Figure 1. Membership of Annamocarya sinensis individuals in a number of presumed populations $(\mathbf{A} . \mathrm{K}=2 ; \mathbf{B}$. $\mathrm{K}=3$ ). Each vertical line represents an individual's probability of belonging to one $\mathrm{K}$ cluster or a combination if ancestry was mixed. Population order: Sandu, Funing, Malipo. 


\section{Isolation by distance and bottleneck}

Significant excess heterozygosity was detected under the assumption of the IAM, which was not detected for all three populations under the SMM or TPM. The discrepancy between the three models was probably caused by different $H_{\mathrm{E}}$ at mutation equilibrium (Luikart and Cornuet, 1998). Given that microsatellite loci are not expected to evolve strictly according to the SMM, a combination of SMM (70\%) and IAM (30\%) - namely TPM - is recommended (Di Rienzo et al., 1994; Spencer et al., 2000). In addition, none of the 3 populations displayed a shifted distribution in allele frequencies (Table 4). No correlation was found between the genetic and geographic distances according to the Mantel test (data not shown).

Table 4. Mutation-drift test under three models and model shift by BOTTLENECK.
\begin{tabular}{llccc}
\hline Population & IAM & SMM & TPM & Model shift \\
\hline SD & $0.00671^{* *}$ & 0.25928 & 0.74072 & Normal \\
FN & $0.03198^{*}$ & 0.11670 & 0.395651 & Normal \\
MLP & $0.00171^{* *}$ & 0.23486 & 0.36670 & Normal \\
\hline
\end{tabular}

IAM = infinite allele model; SMM $=$ stepwise mutation model; TPM $=$ two-phase model; Model shift $=$ shifted distribution of allele frequencies. ${ }^{*} \mathrm{P}<0.05,{ }^{* *} \mathrm{P}<0.01$. For population abbreviations, see Table 1.

\section{DISCUSSION}

Both evolutionary biologists and conservation managers have for some time been interested in knowing that generalities can be made with regard to rare species - e.g., whether they exhibit reduced genetic diversity or restricted gene flow between populations as predicted by population genetic theory when populations are small and isolated (Avise and Hamrick, 1996; Hedrick, 2001). Analyses of the partitioning of genetic variation and population structure are important for an executable conservation strategy, especially if only some of the populations can be protected. With a low population structure level, the loss of a single population may have little impact on species-wide genetic diversity, but with a high structure level, the loss of a single population might significantly reduce overall genetic variation (Ellis et al., 2006).

Given their small population size and endemic character, we had expected $A$. sinensis populations to be genetically impoverished (Sosa et al., 2010). To determine whether this rare species exhibits low diversity, a measure or standard for comparison is required. Many studies of rare plants have made comparisons with other species that have a close phylogeny or share a similar life history. No previous genetic study of $A$. sinensis has used molecular markers, but Juglandaceae, especially Juglans and Carya, have been comprehensively investigated. Qi (2010) has compared species from sections Juglans, Cardiocaryon, and Rhysocayon (with average $H_{E} \mathrm{~s}$ of $0.312,0.176$, and 0.315 , respectively) and section Trachycaryon (data not shown), which divided into Juglans. Zhang (2010) has detected a relatively high level of diversity for walnut in Xinjiang, China, with $N_{\mathrm{A}}=2-15, N_{\mathrm{E}}=1.153-3.397$, mean $H_{\mathrm{O}}=0.457$, and mean $H_{\mathrm{E}}=0.520$. In the present study, genetic diversity $\left(N_{\mathrm{A}}=2-13, N_{\mathrm{E}}=1.320-8.340\right.$, mean $H_{\mathrm{O}}=0.586$, and mean $H_{\mathrm{E}}=0.582$ ) was relatively higher than the above genetic statistics. Compared with that in other endangered endemic perennial species [e.g., Berchemiella wilsonii var. pubipetiolata; $H_{\mathrm{E}}=0.503$ (Kang et al., 2008) and Sambucus palmensis; $H_{\mathrm{E}}=0.500$ (Sosa et al., 2010)], the genetic diversity detected in A. sinensis was higher. 
However, A. sinensis showed a low level of population differentiation as evidenced by a high level of historical gene flow (5.209; data not shown), low F-statistics between paired populations $(0.066)$, and $13 \%$ genetic variability among populations. At the same time, the Wilcoxon test under the IAM model and negative inbreeding coefficient $(-0.024)$ and $H_{\mathrm{O}}(0.586)>H_{\mathrm{E}}(0.582)$ at the population level showed that this species has an excess of heterozygosity. Taken together, these results suggest convincing conclusions: $A$. sinensis has significant excess of heterozygosity, and the populations had undergone a recent bottleneck.

Reproductive systems and the history of a species have often been regarded as the main factors that affect levels of genetic diversity, genetic divergence, and genetic structure within and among populations (Loveless and Hamrick, 1984). According to Hamrick and Godt (1989, 1996), reproductive biology is the most important factor, and outcrossing perennials generally exhibit higher levels of genetic variability and lower levels of population differentiation.

Most species of walnut display a hybridity and auto-incompatibility mechanism (Zhang, 2010; Qi, 2010) with many morphological characteristics, such as wind-pollinated flowers, separated male and female inflorescences, and dichogamy (Lu et al., 1999). A. sinensis has the same characteristics (Lu et al., 1999). In a field survey, we obtained some nuts from the mother tree, which was several kilometers away from another tree in Yongfu, Xichou, and Nandan. However, only 6.2\% (data not published) of these nuts produced viable seeds, progeny vigor was lower, and recruitment was 0 (personal observation). In Sandu, with a relatively large population of 19 adult individuals in an area of $1 \mathrm{~km}^{2}$, many seedlings of different ages and a number of immature individuals were present, showing natural regeneration in good conditions. Taken together, we theorized that $A$. sinensis is an outcrossing perennial.

Conversely, the high level of genetic diversity and low level of population differentiation in species with small populations and few individuals within each population may be an indication that the number of individuals of these species was larger in the recent past (Ellstrand and Elam, 1993; Crawford et al., 2001; Prohens et al., 2007). However, the precise historical distribution and population sizes for A. sinensis are difficult to estimate because of its rarity in the wild, but we might propose that some of the main causes of the considerable reduction in individuals and the current fragmented and isolated distribution are the loss of habitat and excessive deforestation. For example, in many areas, including Sanjiang and Tongdao, naturally occurring individuals were reportedly present in 2003 (Gu, 2003); however, no additional individuals were found during this survey (personal observation).

From a conservation point of view, to avoid breaking co-adapted gene complexes, each population should be protected separately because they are genetically differentiated. However, promoting sexual reproduction among different genotypes and establishing an outcrossing program is more advisable for $A$. sinensis because the relatively low level of genetic differentiation among wild populations and the high level of historical gene flow will likely minimize the possibility of outbreeding depression. In addition, the conservation strategy should focus on protecting as many individuals and populations as possible and increasing the sizes of small populations to minimize further loss of genetic variation and artificially assist gene flow. The Sandu, Funing, and Malipo populations should serve as a valuable baseline for monitoring of the effectiveness of establishing protected areas and restoring and maintaining genetic diversity in A. sinensis. 


\section{ACKNOWLEDGMENTS}

We thank Guangying Nong, Po Xiao, Jian Liu, and Guangpei Wen for the assistance in plant sampling. We also acknowledge Dr. Jijun Tang of the University of South Carolina (Carolina) and Dr. Ming Kang of the South China Botanic Garden, Chinese Academy of Sciences (Guangzhou) for their valuable comments and suggestions for revising the manuscript. Research supported by the Project of the Field Ambulance and Breeding of Rare and Endangered Species (\#1691300105002) of the Wild Conservation and Nature Reserve Management Division of the State Forestry Administration.

\section{REFERENCES}

Avise JC and Hamrick JL (1996). Conservation genetics: case histories from nature. Chapman and Hall, New York.

Cole CT (2003). Genetic variation in rare and common plants. Annu. Rev. Ecol. Evol. Syst. 34: 213-237.

Crawford DJ, Ruiz E, Stuessy TF, Tepe E, et al. (2001). Allozyme diversity in endemic flowering plant species of the Juan Fernandez Archipelago, Chile: ecological and historical factors with implications for conservation. Am. J. Bot. 88: 2195-2203.

Di Rienzo A, Peterson AC, Garza JC, Valdes AM, et al. (1994). Mutational processes of simple-sequence repeat loci in human populations. Proc. Natl. Acad. Sci. U. S. A. 91: 3166-3170.

Doyle JJ and Doyle JL (1987). A rapid DNA isolation procedure for small quantities of fresh leaf tissue. Phytochem. Bull. 19: $11-15$.

Elam DR (1998). Population Genetics of Vernal Pool Plants: Theory, Data and Conservation Implications. In: Ecology, Conservation and Management of Vernal Pool Ecosystems (Witham CW, Bauder ET, Belk D, Ferren WR Jr, et al., eds.). California Native Plant Society, Sacramento, 180-189.

Ellis JR, Pashley CH, Burke JM and McCauley DE (2006). High genetic diversity in a rare and endangered sunflower as compared to a common congener. Mol. Ecol. 15: 2345-2355.

Ellstrand NC and Elam DR (1993). Population genetic consequences of small population size: implications for plant conservation. Annu. Rev. Ecol. Syst. 24: 217-242.

Evanno G, Regnaut S and Goudet J (2005). Detecting the number of clusters of individuals using the software STRUCTURE: a simulation study. Mol. Ecol. 14: 2611-2620.

Excoffier LG and Schneider S (2005). Arlequin ver 3.0: an integrated software package for population genetics data analysis. Evol. Bioinf. Online 1: 47-50.

Excoffier L, Smouse PE and Quattro JM (1992). Analysis of molecular variance inferred from metric distances among DNA haplotypes: application to human mitochondrial DNA restriction data. Genetics 131: 479-491.

Falk DA (1992). From Conservation Biology to Conservation Practice: Strategies for Protecting Plant Diversity. In: Conservation Biology: the Theory and Practice of Nature Conservation, Preservation, and Management (Fiedler PL and Jain SK, eds.). Chapman \& Hall, New York, 397-431.

Goudet J (1995). FSTAT Version 1.2: a computer program to calculate F-statistics. J. Hered. 86: 485-486.

Gu YC (2003). Status quo of China's state priority protected wild plants. Cent. S. Forest Inventory Plann. $22: 1-7$.

Gupta PK, Balyan HS, Sharma PC and Ramesh B (1996). Microsatellites in plants: a new class of molecular markers. Curr. Sci. India 45: 45-54.

Hamrick JL and Godt M (1989). Allozyme Diversity in Plant Species In: Population Genetics and Germplasm Resources in Crop Improvem Ent (Brown AHD, CIegg MT and Khler AI, eds.). Sinauer, Sunderland, 44-64.

Hamrick JL and Godt MJW (1996). Effects of life history traits on genetic diversity in plant species. Biol. Sci. 351: 12911298.

Hamrick JL, Godt MJW, Murawski DA and Loveless MD (1991). Correlations Between Species Traits and Allozyme Diversity: Implications for Conservation Biology. In: Genetics and Conservation of Rare Plants (Falk D and Holsinger K, eds.). Oxford Press, London, 75-86.

Hedrick PW (2001). Conservation genetics: where are we now? Trends Ecol. Evol. 16: 629-636.

Kang M, Wang J and Huang H (2008). Demographic bottlenecks and low gene flow in remnant populations of the critically endangered Berchemiella wilsonii var. pubipetiolata (Rhamnaceae) inferred from microsatellite markers. Conserv. Genet. 9: 191-199.

Karron JD (1987). A comparison of levels of genetic polymorphism and self-compatibility in geographically restricted and 
widespread plant congeners. Evol. Ecol. 1: 47-58.

Leigh F, Lea V, Law J, Wolters P, et al. (2003). Assessment of EST-and genomic microsatellite markers for variety discrimination and genetic diversity studies in wheat. Euphytica 133: 359-366.

Loveless MD and Hamrick JL (1984). Ecological determinants of genetic structure in plant populations. Annu. Rev. Ecol. Syst. 15: 65-95.

Lu AM, Stone DE and Grauke LJ (1999). Juglandaceae. Flora China 4: 277-285.

Luikart G and Cornuet JM (1998). Empirical evaluation of a test for identifying recently bottlenecked populations from allele frequency data. Conserv. Biol. 12: 228-237.

Mantel N (1967). The detection of disease clustering and a generalized regression approach. Cancer Res. 27: 209-220.

Marshall TC, Slate J, Kruuk LE and Pemberton JM (1998). Statistical confidence for likelihood-based paternity inference in natural populations. Mol. Ecol. 7: 639-655.

Peakall R and Smouse PE (2006). GENALEX 6: genetic analysis in Excel. Population genetic software for teaching and research. Mol. Ecol. Notes 6: 288-295.

Piry S, Luikart G and Cornuet JM (1999). BOTTLENECK: A Program for Detecting Recent Effective Population Size Reductions from Allele Data Frequencies. Montpellier, France.

Pritchard JK, Stephens M and Donnelly P (2000). Inference of population structure using multilocus genotype data. Genetics 155: 945-959.

Prohens J, Anderson GJ, Herraiz FJ, Bernardello G, et al. (2007). Genetic diversity and conservation of two endangered eggplant relatives (Solanum vespertilio Aiton and Solanum lidii Sunding) endemic to the Canary Islands. Genet. Resour. Crop Evol. 54: 451-464.

Qi JX (2010). Study on germplasm of Juglans L. by SSR markers. Master's thesis, China Agricultural University, Beijing.

Reed DH and Frankham R (2003). Correlation between fitness and genetic diversity. Conserv. Biol. 17: 230-237.

Rungis D, Berube Y, Zhang J, Ralph S, et al. (2004). Robust simple sequence repeat markers for spruce (Picea spp.) from expressed sequence tags. Theor Appl. Genet. 109: 1283-1294.

Schneider S, Roessli D and Excoffier L (2000). ARLEQUIN. A Software for Population Genetics Data Analysis (Version 2.000). Genetics and Biometry Laboratory. University of Geneva, Geneva.

Sosa PA, González-Pérez MA, Moreno C and Clarke JB (2010). Conservation genetics of the endangered endemic Sambucus palmensis Link (Sambucaceae) from the Canary Islands. Conserv. Genet. 11: 2357-2368.

Spencer CC, Neigel JE and Leberg PL (2000). Experimental evaluation of the usefulness of microsatellite DNA for detecting demographic bottlenecks. Mol. Ecol. 9: 1517-1528.

Spielman D, Brook BW and Frankham R (2004). Most species are not driven to extinction before genetic factors impact them. Proc. Natl. Acad. Sci. U. S. A. 101: 15261-15264.

Toth G, Gaspari Z and Jurka J (2000). Microsatellites in different eukaryotic genomes: survey and analysis. Genome Res. 10: $967-981$.

Zhang R (2010). Studies on the Genetic Diversity and Phylogeny of Walnut in XinJiang. Master's thesis, Huazhong Agricultural University, Wuhan. 